\title{
Pain control options for first trimester surgical abortion: a review
}

\author{
Miriam E.W. Murray, BA, ${ }^{1}$ Abbey J. Hardy-Fairbanks, MD, ${ }^{2}$ Adrianne R. Racek, MD, ${ }^{2}$ \\ Colleen K. Stockdale, MD, MS ${ }^{2}$
}

Keywords: Analgesia, abortion, first trimester surgical abortion, surgical abortion, pain

\begin{abstract}
Pain control is a significant issue for women undergoing gynecological procedures including first trimester surgical abortion. Pain perception is a complex phenomenon which impacts the selection of analgesia. We present a review on the efficacy of various pain control modalities for first trimester surgical abortion in the clinical setting.

${ }^{1}$ University of lowa Carver College of Medicine, lowa City, lowa

${ }^{2}$ University of lowa Hospitals and Clinics, Department of Obstetrics and Gynecology, lowa City, lowa
\end{abstract}

\section{Background}

Pain control is a significant issue for women during gynecologic procedures including first trimester surgical abortion. Pain perception is a complex phenomenon with physical and psychosocial interactions which vary considerably among women. While a variety of options are available for analgesia, evidence elucidating the efficacy of these options is limited. Currently, selection of analgesia for first trimester surgical abortion is primarily guided by literature on other gynecological procedures involving dilation of the cervix in conscious patients. While these studies provide useful insight, the issue of pain control during abortion is complicated not only by the psychosocial aspects of pain, but also by the context of a procedure so deeply stigmatized as abortion.

The primary aim of this paper is to review the currently available literature on the efficacy of various pain control modalities during first trimester surgical abortion excluding general and regional anesthesia.

\section{Methods}

Articles were identified through a PubMed database search using the $\mathrm{MeSH}$ search terms "therapeutic abortion" and "acute pain" or "analgesia". Relevant articles involving

Please cite this paper as: Murray MEW, Hardy-Fairbanks, AJ, Racek AR, Stockdale CK. Pain control options for first trimester surgical abortion: a review. Proc Obstet Gynecol. 2014;4(2): Article 2 [ 6 p.]. Available from: http://ir.uiowa.edu/pog/. Free full text article.

Corresponding author: Miriam M. E. Murray, University of lowa Carver College of Medicine, lowa City, Iowa. miriam-murray@uiowa.edu.

Financial Disclosure: The authors report no conflict of interest.

Copyright: (c) 2014 Murray et al. This is an open-access article distributed under the terms of the Creative Commons Attribution License, which permits unrestricted use, distribution, and reproduction in any medium, provided the original author and source are credited. 
women who underwent first trimester surgical abortion in the clinic setting to August 2014 were included.

\section{Results}

There was considerable heterogeneity of analgesia regimens which limits comparison of analgesia methods for first trimester surgical abortion. No technique provided reliable let alone superior pain control. A brief review of pharmacologic and nonpharmacologic options is provided.

\section{Pharmacologic}

\section{Paracervical block}

Paracervical blocks are used widely in gynecologic procedures including first trimester surgical abortion. Several studies have been performed that specifically investigate the efficacy of paracervical block for pain control during surgical abortion. Glanz et al noted chloroprocaine was superior to saline in a 4 arm randomized trial involving 82 women undergoing first trimester aspiration abortion. ${ }^{1}$ Women reported significantly less pain during dilation and aspiration as well as after the procedure. $^{1}$

Conversely, a study by Miller et al compared lidocaine and saline in paracervical blocks and found no difference in patients' perception of pain during and after surgical abortion among 52 women who participated in a doubleblind randomized clinical trial. ${ }^{2}$ A similar study by Kan et al demonstrated no difference in reported pain during dilation, aspiration, or following the procedure when comparing paracervical block with lidocaine compared to saline placebo or to no injection in a randomized trial involving 135 women undergoing first trimester suction evacuation. All women received cervical priming with misoprostol and received intravenous sedation. ${ }^{3}$ Thus, the trial by Kan may be limited by small study size and the use of intravenous sedation.

A Cochrane review performed in 2013 identified no clear evidence of superiority or inferiority using paracervical blocks over other methods for pain control during procedures involving cervical dilation and uterine instrumentation. While this review was not specifically directed toward the use of paracervical blocks during surgical abortions, it provides a strong basis to question the utility regarding the continued use of this method. ${ }^{4}$

\section{Conscious sedation}

While conscious sedation is frequently utilized in surgical abortions and other procedures, the efficacy of conscious sedation on reducing pain during first trimester surgical abortions has not been well studied. Wong et al found no significant differences in reported pain between 100 women undergoing first trimester suction evacuation with conscious sedation with intravenous midazolam and fentanyl versus placebo. $^{5}$ However women reported increased satisfaction when the procedure was performed under conscious sedation (5). Wells et al found that among 84 women evaluated for distress during first trimester abortion, those who received intravenous sedation with diazepam and fentanyl compared to placebo (with each group 
as an adjuvant to paracervical block) reported significantly less distress and pain. ${ }^{6}$

\section{Topical anesthetic}

The low cost and minimal risk associated with the use of topical anesthetics for pain control during procedures involving cervical dilation and uterine manipulation has led to a recent increase in studies investigating their use during such procedures with some promising results. Unfortunately, very few of these studies have focused on the use of topical anesthetics during abortion.

A randomized placebo-controlled double-blind study involving 131 women investigated the application of topical lidocaine gel to the cervix during first trimester surgical abortion, the results of which suggested a minor effect on decreasing intra-procedural pain in multiparous women. ${ }^{7}$ Two randomized, double-blind, placebo control studies by Edelman et al investigated the use of intrauterine lidocaine infusion as an adjuvant to paracervical block in first trimester surgical abortions. These studies found that intrauterine infusion of $1 \%(10 \mathrm{~mL})$ lidocaine did not lead to a significant decrease in reported pain as compared to placebo, but $4 \%(5 \mathrm{~mL})$ lidocaine infusion did significantly reduce pain perception $(p<0.01){ }^{8,9}$

\section{Premedication}

Premedication with both nonsteroidal antiinflammatory drugs (NSAIDs) and benzodiazepines is common practice for surgical abortion. Several studies have shown evidence that NSAIDs given before the procedure provide a significant decrease in patients reported pain compared to placebo. ${ }^{10,11}$ Premedication with lorazepam was not shown to decrease reported pain during the procedure. ${ }^{10}$

\section{Non-pharmacologic}

Several studies investigated the use of music as an adjuvant to paracervical block for pain reduction during surgical abortions. A randomized case-control trial performed by Guerrero et al compared reported pain in patients with routine pain control versus routine pain control plus music and identified a significant reduction in reported pain in the group that listened to music during the procedure. ${ }^{12}$ While the comparison is no longer employed as standard of care, patients reported significantly reduced pain with music therapy as compared to self-administration of the inhaled anesthetic methoxyflurane when investigated nearly 40 years ago as an adjunct to paracervical block for suction curettage. ${ }^{13}$

The use of hypnosis was evaluated in a randomized control trial comparing hypnosis and standard care to standard care among 30 women undergoing first trimester surgical abortion. ${ }^{14}$ Although there were no differences in pain and anxiety during the procedure between the groups, women hypnotized prior to the procedure were less likely to request inhaled analgesia than controls ( $87 \%$ vs $36 \%$, respectively; $p<0.01) .{ }^{14}$

\section{Technique}

While it has been shown in multiple studies that vacuum aspiration is safer 
and less painful than sharp curettage for first trimester abortion, ${ }^{15}$ the choice of manual versus electric is less clear with many heterogeneous studies using variety of pain measurement techniques. ${ }^{16}$ Manual vacuum aspiration offers a lower noise option to electric vacuum aspiration. Dean et al demonstrated that women are often bothered more by the noise $(19 \%$ vs $2 \%, p=0.03$ ) and for procedures at less than 50 days gestation, four trials of over 800 subjects showed a reduction in severe pain. ${ }^{16,17}$ However, a subsequent randomized control trial by Singh et al failed to show improvement in patient perception of pain with manual versus electric vacuum aspiration or specific patient characteristics associated with increased pain perception. ${ }^{18}$

\section{Conclusions}

Options for first trimester surgical abortion pain control are heterogeneous. There is no clearly superior method for pain control during first trimester surgical abortion. The use of multiple methods concurrently may offer benefit and likely provides little to no additional risk (e.g. music therapy, plus premedication, plus paracervical block). Premedication with NSAIDs and playing music have both been demonstrated to be of possible benefit in improving pain control during surgical abortions. Both modalities can be used in conjunction with other pain control methods, are inexpensive, and carry little to no risk. The continued use of these methods is well supported by the available literature. Sharp curettage should be avoided, but there is not enough evidence at this time to recommend manual vacuum aspiration over electric based on pain perception alone.

The surprisingly limited data in support of the efficacy of paracervical block during surgical abortions calls for further research of this widely accepted practice. While this form of analgesia is a relatively low-risk option, there is an approximately $10 \%$ incidence of vasovagal reaction with cervical injections ${ }^{1}$ as well as a small risk of accidental vascular administration of an anesthetic that can cause systemic toxicity. The unclear efficacy of paracervical block should be considered with each patient when the relative risks and benefits are considered.

While conscious sedation has not consistently shown to improve pain control, studies indicate patient satisfaction is improved and distress is decreased in those patients who receive conscious sedation. This information is important to take into consideration in counseling patients regarding expectations with the use of conscious sedation.

Ultimately, further research is needed in all aspects of abortion care and pain control is no exception. Continuing to be mindful of the patient and the many interacting factors that lead to the experience of pain is important to minimize pain associated with the procedure. 


\section{References}

1. Glantz JC, Shomento S. Comparison of paracervical block techniques during first trimester pregnancy termination. Int J Gynaecol Obstet. 2001 Feb;72(2):1718. http://dx.doi.org/10.1016/S00207292(00)00292-7. PubMed PMID: 11166751.

2. Miller L, Jensen MP, Stenchever MA. A double-blind randomized comparison of lidocaine and saline for cervical anesthesia. Obstet Gynecol. 1996 Apr;87(4):600-4. http://dx.doi.org/10.1016/00297844(95)00463-7. PubMed PMID: 8602315.

3. Kan AS, Ng EH, Ho PC. The role and comparison of two techniques of paracervical block for pain relief during suction evacuation for first-trimester pregnancy termination. Contraception. $2004 \quad$ Aug;70(2):159-63. http://dx.doi.org/10.1016/j.contraception. 2004.03.013. PubMed PMID: 15288222.

4. Tangsiriwatthana $T$, Sangkomkamhang US, Lumbiganon P, Laopaiboon M.Paracervical local anaesthesia for cervical dilatation and uterine intervention. Cochrane Database Syst Rev. 2013 Sep 30;9:CD005056. doi: 10.1002/14651858.CD005056.pub3.

PubMed PMID: 24085642.

5. Wong $\mathrm{CY}, \mathrm{Ng} \mathrm{EH}$, Ngai SW, Ho PC. A randomized, double blind, placebocontrolled study to investigate the use of conscious sedation in conjunction with paracervical block for reducing pain in termination of first trimester pregnancy by suction evacuation. Hum Reprod. $2002 \quad$ May;17(5):1222-5. http://dx.doi.org/10.1093/humrep/17.5.1 222. PubMed PMID: 11980742.
6. Wells N. Reducing distress during abortion: a test of sensory information. J Adv Nurs. 1992 Sep;17(9):1050-6. http://dx.doi.org/10.1111/j.13652648.1992.tb02039.x. PubMed PMID: 1401546.

7. Li HW, Wong CY, Lo SS, Fan SY. Effect of local lignocaine gel application for pain relief during suction termination of first-trimester pregnancy: a randomized controlled trial. Hum Reprod. 2006 Jun;21(6):1461-6. Epub 2006 Feb 14. http://dx.doi.org/10.1093/humrep/del023 . PubMed PMID: 16478762.

8. Edelman A, Nichols MD, Leclair C, Astley S, Shy K, Jensen JT. Intrauterine lidocaine infusion for pain management in first-trimester abortions. Obstet Gynecol. 2004 Jun;103(6):1267-72. http://dx.doi.org/10.1097/01.AOG.00001 27981.53911.0e. PubMed PMID: 15172863.

9. Edelman A, Nichols MD, Leclair C, Jensen JT. Four percent intrauterine lidocaine infusion for pain management in first-trimester abortions. Obstet Gynecol. 2006 Feb;107(2 Pt 1):269-75. DOI:

10.1097/01.AOG.0000194204.71925.4a . PubMed PMID: 16449111.

10. Renner RM, Jensen JT, Nichols MD, Edelman $A B$. Pain control in firsttrimester surgical abortion: a systematic review of randomized controlled trials. Contraception. 2010 May;81(5):372-88. doi:

10.1016/j.contraception.2009.12.008. Epub 2010 Jan 27. PubMed PMID: 20399943.

11. Suprapto K, Reed S. Naproxen sodium for pain relief in first-trimester abortion. Am J Obstet Gynecol. 1984 Dec 15;150(8):1000-1. http://dx.doi.org/10.1016/00029378(84)90399-5. PubMed PMID: 6507524 . 
12. Guerrero JM, Castaño PM, Schmidt EO, Rosario L, Westhoff CL. Music as an auxiliary analgesic during first trimester surgical abortion: a randomized controlled trial. Contraception. 2012 Aug;86(2):157-62. 10.1016/j.contraception.2011.11.017. Epub 2012 Jan 10. PubMed PMID: 22240180.

13. Shapiro AG, Cohen H. Auxiliary pain relief during suction curettage. Contraception. 1975 Jan;11(1):25-30. http://dx.doi.org/10.1016/00107824(75)90047-5. PubMed PMID: 1116357.

14. Marc I, Rainville $P$, Verreault $R$, Vaillancourt L, Masse B, Dodin S. The use of hypnosis to improve pain management during voluntary interruption of pregnancy: an open randomized preliminary study. Contraception. 2007 Jan;75(1):52-8. Epub $2006 \quad$ Sep 20. http://dx.doi.org/10.1016/j.contraception. 2006.07.012 . PubMed PMID: 17161125 .

15. World Health Organization. Safe Abortion: Technical and Policy Guidance for Health Systems. Geneva, Switzerland: WHO, 2003. http://whqlibdoc.who.int/publications/200 3/9241590343.pdf.

16. Wen J, Cai QY, Deng F, Li YP. Manual versus electric vacuum aspiration for first-trimester abortion: a systematic review. BJOG. 2008 Jan;115(1):5-13. http://dx.doi.org/10.1111/j.14710528.2007.01572.x. PubMed PMID: 18053098.

17. Dean G, Cardenas L, Darney $P$, Goldberg A. Acceptability of manual versus electric aspiration for first trimester abortion: a randomized trial. Contraception. 2003 Mar;67(3):201-6. http://dx.doi.org/10.1016/S00107824(02)00485-7. PubMed PMID: 12618254.
18. Singh $\mathrm{RH}$, Ghanem KG, Burke $A E$, Nichols MD, Rogers K, Blumenthal PD. Predictors and perception of pain in women undergoing first trimester surgical abortion. Contraception. 2008 Aug;78(2):155-61.

doi: 10.1016/j.contraception.2008.03.011. Epub 2008 May 27. PubMed PMID: 18672118. 